\title{
Exploring the Influence of Quality and Safety on Consumers' Food Purchase Decisions in Botswana
}

\author{
Botshabelo Kealesitse (Corresponding author) \\ Department of Marketing \\ University of Botswana \\ Private bag 701 \\ Gaborone, Botswana \\ Tel: +267-727-85237Ｅ-mail: kealesit@mopipi.ub.bw, kealesitse@yahoo.com \\ Ivy Ontlametse Kabama \\ Department of Marketing \\ University of Botswana \\ Private Bag 701 \\ Gaborone, Botswana \\ E-mail: kabamaont@yahoo.com
}

Received: October 19, 2011

Accepted: February 10, 2012 Published: March 15, 2012

doi:10.5430/ijba.v3n2p90

URL: http://dx.doi.org/10.5430/ijba.v3n2p90

\begin{abstract}
The main purpose of this research was to gain some exploratory insights into how important food quality and safety issues were in influencing Botswana customers' food purchase decisions. A cross-sectional descriptive research design utilising a structured questionnaire was used to collect data from a sample of 150 respondents who reside in Gaborone, Botswana in January 2011. The study found that in defining quality and safety of food, consumers used the same attributes thus resulting in an overlap in definitions of the two concepts. It also revealed that both food quality and safety were considered important by consumers. Consumers also perceived a relationship between quality and safety as they believed the two to be related. The implication from this research is that, consumers in developing countries such as Botswana also have concerns regarding food quality and safety and that the two concepts are important in their daily food choices.
\end{abstract}

Keywords: Consumers, Perceptions, Food Quality, Food Safety, Purchase Decisions

\section{Introduction}

Globally, food safety and quality have received increased attention from both consumers and researchers (Naspetti and Zanoli 2009). According to research, consumers generally prefer food products that are safe and of high quality (Grunert, 2005). Consumers' concern about the safety and quality of food tends to affect their future intentions to purchase food (Smith \& Riethmuller, 2000). In fact research shows that there was an inverse relationship between safety concerns and intended future consumption (Smith \& Riethmuller, 2000). Food quality and safety are so important that consumers are even willing to pay a premium over the normal price as long as they have a guarantee about the safety and quality of the food they purchased (Ortega, Wang, Wu, \& Olynk, 2011; Wilcocky, Pun, Khanonax, \& Aung, 2004). Therefore, food quality and safety are important in influencing consumers' perceptions and decisions regarding food product choices.

Despite the importance of food quality and safety on consumers' food choice, there has been very limited research on issues relating to food quality and safety in Botswana. Most research into this issue has focused on the developed countries, especially Europe, (Rijswijk and Frewer, 2008; Grunert, 2005), and left behind countries in Africa which are equally affected by issues relating to quality and safety of food (Ohiokpehai, 2003; Omemu and Aderoju 2008). Unlike their African counterparts, consumers in developed countries have the advantage of exposure to information and are more likely to know about issues concerning product quality and safety (Omemu and Aderoju 2008). Few studies 
undertaken on food quality and safety in Africa focused mainly on food handling by street vendors and did not adequately seek to understand how consumers perceived food quality and safety (Ohiokpehai, 2003; Omemu and Aderoju 2008). A study undertaken in Botswana by Mburu and Paulos (2010) was more on consumers' perceptions of in-store prepared food. This also did not adequately consider consumers' perceptions regarding the issues of food safety and quality.

The consequences of poor food quality and safety are more likely to affect customers as they are the ultimate consumers of the purchased food. In fact, research indicates that food-borne illnesses are associated with unhygienic handling and that less emphasis on quality and safety are common in Africa (Omemu and Aderoju 2008). In Botswana, food quality and safety are of high importance given the problem of HIV/AIDS. Furthermore, Foot and Mouth Disease is common in some parts of Botswana and this may affect the safety of meat products. This puts consumers' health at risk. It is therefore important to understand how consumers react to issues of food quality and safety in Botswana. This study seeks to investigate how food quality and safety affect customers' food purchase decisions in Botswana.

\section{Objectives of the Study}

The main objective of this study was to investigate the importance of food quality and safety on consumers' food purchases in Botswana. The specific objectives are:

1. To explore consumers' awareness of food safety and quality when buying food.

2. To investigate the importance of both quality and safety in consumers' food purchase decisions.

\section{Theoretical Foundation}

In today's world, consumers have become more demanding, critical, and more fragmented in their food choices (Grunert 2005). Food purchase decisions are largely influenced by quality and safety considerations (Wilcock et al., 2004). Emphasis on quality and safety is partly driven by health reasons (Grunert, 2005). According to Miles et al. (2004), consumers could be exposed to a number of food hazards associated with their food choice decisions and consumption behaviors. Fortunately consumers, more especially in the developed world, are aware of these risks and have become more discriminative with their food product choices (Rohr et al. 2005).

The argument over food safety and quality has expanded to include issues surrounding how food was produced. For example, research shows that consumers were now concerned about chemical substances which have either been deliberately or accidently included in food items such as hormones, pesticides, veterinary drugs, and packaging components. Consumers are also concerned about food processing methods affecting the quality and safety of food (Yeung \& Morris 2001; Spence \& Townsend 2006) as well as microbiological contaminants (Macfarlane, 2002; Wilcock et al., 2004).

Perceived risks of technological and biological origins have been the focus of concern within the media and the public (Behrens, Barcellos, Frewer, Nunes, \& Franco, 2010). For example, the dioxin scare and BSE outbreak in Europe (de Jonge et al., 2004; Macfarlane, 2002; Wilcock et al., 2004) and the recent (2011) E-coli outbreak in Germany (www.bbc.co.uk/news). Therefore, consumers' general confidence in the quality and safety of food products has largely been influenced by the level of trust they have in the actors within the supply chain (de Jonge et al., 2004) who are normally linked to the risk of food contamination during production and distribution of food.

\subsection{Definitions and Importance of Food Quality and Safety}

Consumers' definition of food quality can generally be categorised into four dimensions which include taste, appearance, health, process and convenience (Naspetti and Zanoli 2009). Some characteristics of food such as taste, appearance and smell are used to constitute a central dimension of quality for most consumers. This trend has however changed over the years as consumers are believed to have shown an increasing interest in other quality dimensions as well. With regards to health dimension, consumers form preferences on the basis of how the food product will impact on their health. Consumers have also shown interest on the process followed when food is produced starting from the farm up to the food processing level (Grunert 2005). Their interest mostly evolved around issues concerning organic production of food, animal welfare and the use of genetically modified organisms in producing food (Grunert 2005). Another factor of increasing importance in assessing food quality by consumers is convenience. Convenience covers saving of time and effort spent on buying, storing preparing and consumption of food (Naspetti and Zanoli 2009). Consumers prefer to save time and effort when buying, storing and preparing their food. A study by Mburu and Paulos (2010) observed that both health and convenience played an important role in influencing Botswana customers' desire to purchase in store cooked food. 
Food safety can be objectively defined by scientists and experts as a concept mainly based on the assessment of the risk of consuming certain food products (Grunert 2005). In other words it is ... "the probability of not contracting a disease as a consequence of consuming certain food"... Grunert 2005, p.381). It relates to consumers' risk perception of inadvertently consuming harmful substances forming part of their food (Naspetti and Zanoli 2009). It may also include consumers' concerns relating to food production and handling within the supply chain (Grunert 2005). Consumers are fearful of consuming poisonous chemical substances such as fertilisers and pesticides which come in contact with food during production (Naspetti and Zanoli 2009). Safety is therefore influenced a lot by the trust that consumers have on the producer and methods of production (Naspetti and Zanoli 2009). The presence of perceived risk would negatively impact consumers' food choice decisions and result in reduced consumption (Burton and Young 1996; Grunert 2005).

Rijswijk and Frewer (2008) observed considerable overlaps between consumers' definitions of quality and safety. For example, some consumers may include quality in their definition of safety attributes, and vice versa, which may support the idea that these two concepts are interrelated in consumers' views. For many people, safety has been said to represent one aspect of quality, and therefore finding a product that is of high quality also implies that it is safe. However, the reverse relationship does not necessarily hold, implying that safety seems to be a basic ingredient for quality while quality is not necessarily safety (Rijswijk and Frewer 2008).

\section{Methodology}

\subsection{Sampling Frame}

The sampling frame comprised adults who reside in Gaborone (Botswana) and were responsible for purchasing food on behalf of their households. A sample of 200 was envisaged for the study but this proved difficult to get due to some logistical issues. The researcher managed to get 150 respondents. The sample size was however considered acceptable because similar studies used sample sizes ranging from 120-260 (Rijswijk and Frewer. 2008). Non-probability sampling technique was used for this study, more specifically convenience sampling. Respondents were intercepted in malls, and other public areas. The method was advantageous because of the speed at which information was collected, its low cost and availability of elements of the population.

\subsection{Data Collection}

A self administered structured questionnaire was used for data collection. Questionnaire items were adapted from an exploratory study on consumers' perceptions of food quality and safety by Rijswijk and Frewer, (2008). The questionnaire consisted of both closed and open ended questions. A four point Likert scale was used where "1" represented "strongly disagree", in some questions, "extremely unimportant" and "4" represented "strongly agree " or "extremely important." The questionnaire was divided into five sections. Section 1 was the definition of food quality and safety; section 2 contained questions on the influence of quality and safety on customers' food choice; section 3 was the difference between safety and quality; section 4 established the importance of both quality and safety in food choices; section 5 was demographics.

\section{Findings}

\subsection{Demographics}

Results indicate that out of the 150 respondents that took part in the study, 93 were female (62\%) and the remaining 57 were males $(38 \%)$. The majority of the respondents (over $44 \%$ ) were between 22 years and 35 years, while 23 respondents $(15 \%)$ were aged below 21years. The age category of between 36 and 49 years had 42 respondents, accounting for $28.0 \%$ of the respondents while those 50 years and above made up only $12.0 \%$ (18) of the sample. Most of the respondents had attained higher levels of education with 74\% (111) having undergraduate degrees and just over $10 \%$ having postgraduate degrees. Respondents' demographic characteristics are summarized in Table 1.

\subsection{Consumers' Definition of Food Quality and Safety}

To investigate how consumers define food quality and safety, respondents were given a list of attributes adopted from a similar study by Rijswijk and Frewer, (2008). They were asked to rate the relevance of each attribute using likert scale ranging from strongly agree (4) to strongly disagree (1). Results are summarized in Table 2.

Results indicate that "taste" and "freshness" ranked highest in describing food quality. They both shared the highest mean score of 3.37. On the other hand "Price" had the lowest mean score of 2.76. Overall, most attributes had means above 3.00 an indication that while not ranked highest, they were still relevant in describing food quality.

Most respondents felt that the "best before date" was very important in describing food safety. This attribute had the highest mean of 3.55. As was the case with definition of quality, "price" ranked lowest with a mean score of 2.57. Other attributes scored above 3.00, emphasizing their relevance in describing food safety as well. 
An open ended question was provided at the end for consumers to suggest any other factors that they thought were relevant in defining both food quality and safety and the responses obtained included; "nutritional value", "ingredients" and "a good smell".

\subsection{Influence of Quality on Food Purchase Decisions}

Respondents were asked to indicate how quality and safety influenced their food purchase decisions. Results in Table 3 show that consumers' food choices were influenced largely by both quality and safety as the first statement, 'choice based on both quality and safety' returned the highest mean score of 3.39. All the remaining options returned means lower than 2.00, while 'choice based on neither quality nor safety' received the lowest mean score of 1.55.

\subsection{Perceived Relationship between Quality and Safety}

Respondents were requested to indicate whether or not they perceived food quality and safety to be interrelated. The results are summarized in Table 4. Most respondents felt food quality and safety were related though not basically the same. This is explained by a lower mean score of 2.85 for the option that says 'food quality and safety are the same' when compared to the second option (food quality and safety are related) which had a higher mean score of 3.71 . Results also showed that quality somewhat implied safety with a high mean score of 3.13. On the other hand, when respondents were asked whether safety implied quality, the mean score was 3.07 a sign that the inverse relationship was not always true. However, only a small proportion of respondents felt that quality and safety were unrelated, returning a very low mean of 1.49 .

\subsection{Testing For Differences between Males and Females}

To examine if there were any significant differences in regards to how quality and safety influence purchase decisions between males and females, a T-test was performed. Results are summarized in Table 5. As shown in Table 5, there was no statistically significant difference (at significance level 0.05 ) between the males and the females on how quality and safety influenced their purchase decisions.

\section{Discussions}

Results show that generally consumers' definition of food quality and safety tends to overlap. Similar attributes were used for defining both quality and safety and all attributes defining the two concepts returned mean scores ranging from 2.80 to almost 3.40 which was relatively high. The high mean scores indicate that consumers perceived the attributes as relevant in defining both food quality and safety. However, price received the lowest mean score for both food quality and safety definitions. This shows that consumers perceived price as a less relevant determinant of both food quality and safety.

Moreover, consumers seemed to be concerned about the freshness and taste of food which to them denotes quality as well as the best before date denoting safety. Results show that these attributes returned the highest mean scores for quality and safety respectively. It can therefore be deduced that food appearing to be fresh and tasty, and within the best before date, would be perceived as high quality and safe to consume. Unfortunately, best before date alone is not an adequate indication of food safety. In fact, consumers are at risk of buying and consuming unsafe food if they rely too much on the best before date. However, results show that respondents also rated other factors such as freshness, packaging material and guarantee as important in determining food safety. If these factors are considered alongside best before date when making food purchases, then risk of consuming unsafe food could be reduced.

Results further indicate that both quality and safety were important when making food purchase decisions. The choice of food products based on both quality and safety received the highest mean score of 3.39 while other options had mean scores below 2.0. This was a clear indication that consumers cannot afford to ignore both quality and safety in their food purchase decisions. Consumers felt that quality and safety were related and also that good quality implies safety though the reverse relationship is not true. On the basis of these results, it can be concluded that in general, consumers perceive a strong relationship between food quality and safety. Moreover, when people perceive a product as being of good quality it can generally be assumed that the product is also safe to consume.

Finally, there was no significant difference between males and females with regards to the importance of quality and safety in food product choices. The implication is that both males and females are generally influenced by food quality and safety when making their food purchases.

\section{Managerial Implications}

This study has revealed that consumers' choice for food is largely influenced by both quality and safety considerations. These results imply that consumers in developing countries such as Botswana are also aware of the importance of quality and safety in their food purchase decisions. Given the influence that the two concepts have on consumers' 
purchase decisions, food retailers (e.g. Restaurants) should ensure that both quality and safety are strictly observed. Most importantly they should emphasize the freshness of the food and comply with the best before date as these attributes have been identified by respondents as important criteria in determining both food quality and safety respectively. Emphasizing the above criteria makes food vendors more responsive to customers' needs, which is expected to result in high levels of customer satisfaction and loyalty. Given that food quality was linked to safety, retailers should ensure their food is of high quality in order in order appeal to safety expectations of consumers.

Finally, the fact that most respondents gave a higher rating to the best before date as an indication of food safety implies that consumers assume that food is safe to consume as long as it is consumed before its expiry date. However, best before date on its own is not adequate as it does not preclude the existence of other objects such as toxins, fertilizers and genetically modified organisms. Consumers were possibly less aware of the risk posed by other safety considerations. This is somewhat expected, since Botswana is a developing country and information on food safety considerations could be relatively new to some consumers. To tackle this, the Botswana government and other stakeholders should undertake consumer awareness campaigns addressing the importance of food safety.

\section{Conclusions}

In conclusion the study has revealed that both quality and safety are important in consumers' purchase of food. The overlap in the definition of the two concepts is an indication of how important they are to the consumers. It has also been revealed that the concern for safety and quality is not confined to developed countries. Thus, food manufacturers and other players in the supply chain have to observe high levels of quality and safety to address customer expectations. However rating the best before date as the major factor in defining food safety is an indication that awareness on food safety issues is still lacking in Botswana. This calls for concerted efforts on the part of the government to raise awareness to avoid undesirable consequences of consuming harmful and less safe food.

\section{References}

Behrens, J. H., Barcellos, M. N., Frewer, I. J., Nunes, T. P. \& Franco, B. D. (2010). Consumer purchase habits and views on food safety: A Brazilian study. Food control, 21(7), 963-969 http://dx.doi.org/10.1016/j.foodcont.2009.07.018

Burton, M., \& Young T. (1996). The impact of BSE on the demand for beef and other meats in Great Britain. Applied Economics, 28(6), 687-693..http://dx. doi.org/ 10.1080/000368496328434

De Jonge, J., Frewer, L., Van Trijp, H., Renes, R.J., De Wit, W. \& Timmers, J. (2004). Monitoring consumer confidence in food safety: an exploratory study. British Food Journal, 106 (10/11), 837-49..http://dx.doi.org/10.1108/00070700410561423

Grunert, K. G. (2005). Food quality and safety: consumer perception and demand. European Review of Agricultural Economics, 32(3) 369-91. http://dx.doi.org/10.1093/eurrag/jbi011

Hammoudi, A., Hoffmann, R., \& Surry, Y. (2009). Food safety standards and agri-food supply chains: an introductory overview. European Review of Agricultural Economics, 36 (4), 469-478. http://dx.doi.org/10.1093/erae/jbp044

MacFarlane, R. (2002). Integrating the consumers' interest in food safety: The role of the science and other factors. Food Policy, 27 (1), 65-80. http://dx.doi.org/10.1016/S0306-9192(02)00003-9

Mburu, P.T. \& Paulos, K. (2010). Acuity of in-store cooked food retailing:an exploratory study on consumer behaviour on in-store prepared food. Indian Journal of Marketing, 40(6), 41-49.

Miles, S., Brennan, M., Kuznesof, S., Ness, M., Ritson, C. \& Frewer, L. J. (2004). Public worry about specific food safety issues. British Food Journal, 106(1), 9-22. http://dx.doi.org/10.1108/00070700410515172

Naspetti, S. \& Zanoli, R. (2009). Organic food quality and safety perception throughout Europe. Journal of Food Products Marketing, 15 (3), 249-266. htp://dx.doi.org/1.1080/10454440902908019

Ohiokpehai, O. (2003). Nutritional aspects of street foods in Botswana. Pakistan Journal of Nutrition, 2(2), 76-81. http://dx.doi.org/10.3923/pjn.2003.76.81

Omemu, A. M., \& Aderoju S. T. (2008). Food safety knowledge and practices of street food vendors in the city of Abeokuta, Nigeria. Food Control, 19(4), 396-402.h ttp://dx.doi.org/10.1016/j.foodcont.2007.04.021

Ortegar, D. L., Wang, H. H., Wu, L. \& Olynk, N. J. (2011). Modeling heterogeneity in consumer preferences for select food safety. Food Policy, 36(2), 318- 324. http://dx.doi.org/10.1016/j.foodpol.2010.11.030 
Rijswijk, W., \& Frewer J. L. (2008). Consumer perceptions of food quality and safety and their relation to traceability. British Food Journal,(110 (10), 1034-1046. http://dx.doi.org/10.1108/00070700810906642

Rohr, A., Luddecke, K., Drusch, S., Muller, M. J. \& Alvensleben R. V. (2005). Food quality and safety-consumer perception and public health concern. Food Control, 16(8), 649-655. http://dx.doi.org/10.1016/j.foodcont.2004.06.001

Smith, D., \& Riethmuller P. (2000). Consumer concerns about food safety in Australia and Japan. British Food Journal, 102(11), 838-855. http://dx.doi.org/10.1108/03068299910227237

Spence, A., \& Townsend, E. (2006). Implicit attitudes towards genetically modified foods: A comparison of context-free and context-dependent evaluations. Appetite, 46(1), 67-74. http://dx.doi.org/10.1016/j.appet.2005.09.003

Wilcock, A. Pun, M., Khanona, J., \& Aung M. (2004). Consumer attitudes, knowledge and behaviour: a review of food safety issues. Trends In Food Science and Technology, 15(2), 56-66. http://dx.doi.org/10.1016/j.tifs.2003.08.004

Yeung, R. M. W. \& Morris, J. (2001). Food safety risk: Consumer perception and purchase behaviour. British Food Journal, 103(3), 170-186. http://dx.doi.org/10.1108/00070700110386728

http://www.bbc.co.uk/news/world-europe-13691087

Table 1. Demographic characteristics of respondents

\begin{tabular}{|c|c|c|}
\hline \multicolumn{3}{|c|}{ Gender } \\
\hline Variable & Number of respondents $n=150$ & Percentage (\%) \\
\hline Male & 93 & 38 \\
\hline Female & 150 & 62 \\
\hline \multicolumn{3}{|c|}{ Age category } \\
\hline Less than 21 years & 23 & 100 \\
\hline 22-35 years & 67 & 44.7 \\
\hline 36-49 years & 42 & 28 \\
\hline 50 years and above & 18 & 12 \\
\hline \multicolumn{2}{|c|}{} & Education level \\
\hline Primary school & 0 & 15.3 \\
\hline High school & 23 & 74 \\
\hline Undergraduate & 111 & 10.7 \\
\hline Postgraduate & 16 & \\
\hline
\end{tabular}


Table 2. Consumers' definition of food products quality and safety

\begin{tabular}{|c|c|c|c|c|}
\hline Concepts & Consumers' definition attributes & $\mathrm{N}$ & Mean & Standard deviation \\
\hline \multirow[t]{12}{*}{ Quality } & Taste & 150 & 3.37 & .700 \\
\hline & Natural/organic & 150 & 3.29 & .651 \\
\hline & Freshness & 150 & 3.37 & .756 \\
\hline & Not risky & 150 & 2.85 & .939 \\
\hline & Appearance & 150 & 2.94 & .829 \\
\hline & Guarantee & 150 & 3.07 & .812 \\
\hline & Best before date & 150 & 3.33 & .764 \\
\hline & Brand & 150 & 3.10 & .918 \\
\hline & Price & 150 & 2.76 & .925 \\
\hline & Country of origin & 150 & 2.99 & .930 \\
\hline & Good condition & 150 & 3.11 & .787 \\
\hline & Packaging material & 150 & 3.05 & .754 \\
\hline \multirow[t]{12}{*}{ Safety } & Taste & 150 & 2.94 & .936 \\
\hline & Natural/organic & 150 & 3.05 & .896 \\
\hline & Freshness & 150 & 3.41 & .804 \\
\hline & Not risky & 150 & 3.23 & .860 \\
\hline & Appearance & 150 & 2.78 & .954 \\
\hline & Guarantee & 150 & 3.31 & .819 \\
\hline & Best before date & 150 & 3.55 & .738 \\
\hline & Brand & 150 & 2.90 & .880 \\
\hline & Price & 150 & 2.57 & .951 \\
\hline & Country of origin & 150 & 2.89 & .796. \\
\hline & Good condition & 150 & 3.31 & 851 \\
\hline & Packaging material & 150 & 3.34 & .731 \\
\hline
\end{tabular}

Table 3. The influence of quality and safety on food purchase decisions

\begin{tabular}{|c|c|c|}
\hline Statements & N & Mean \\
\hline Choice based on both quality and safety & 150 & 3.39 \\
\hline Choice based on quality only & 150 & 1.87 \\
\hline Choice based on safety only & 150 & 1.85 \\
\hline Choice not influenced by food quality & 150 & 1.83 \\
\hline Choice not influenced by food safety & 150 & 1.79 \\
\hline Choice based on neither quality nor safety & 150 & 1.55 \\
\hline
\end{tabular}


Table 4. Interrelationship between quality and safety

\begin{tabular}{|c|c|c|c|c|c|c|}
\hline \multicolumn{2}{|c|}{} & $\begin{array}{c}\text { Quality and safety } \\
\text { are the same }\end{array}$ & $\begin{array}{c}\text { Quality and safety } \\
\text { are related }\end{array}$ & $\begin{array}{c}\text { Quality } \\
\text { implies safety }\end{array}$ & $\begin{array}{c}\text { Safety implies } \\
\text { quality }\end{array}$ & $\begin{array}{c}\text { Quality and safety } \\
\text { are unrelated }\end{array}$ \\
\hline \multirow{2}{*}{$\mathrm{N}$} & Valid & 150 & 150 & 150 & 150 & 150 \\
\cline { 2 - 7 } & Missing & 0 & 0 & 0 & 0 & 0 \\
\hline \multicolumn{2}{|c|}{ Mean } & 2.85 & 3.71 & 3.13 & 3.07 & 1.49 \\
\hline
\end{tabular}

Table 5. Test of differences on the influence of quality and safety by gender

\begin{tabular}{|c|c|c|c|c|}
\hline & \multicolumn{2}{|c|}{ Mean } & \multirow{2}{*}{$\mathrm{t}$} & \multirow{2}{*}{ Significance } \\
\hline & Male & Female & $\mathrm{t}$ & .488 \\
\hline Choice based on both quality and safety & 3.33 & 3.43 & -.695 & .069 \\
\hline Choice based on quality only & 1.77 & 1.94 & -1.833 & .173 \\
\hline Choice based on safety only & 1.77 & 1.90 & -1.368 & .173 \\
\hline Choice not influenced by food quality & 1.91 & 1.78 & .854 & .394 \\
\hline Choice not influenced by food safety & 1.93 & 1.71 & 1.555 & .122 \\
\hline Choice based on neither quality nor safety & 1.61 & 1.51 & .825 & .411 \\
\hline
\end{tabular}

